\title{
DETERMINAÇÃO DA RESERVA REGULADORA DO AQUÍFERO CAIUÁ NO ESTADO DO PARANÁ UTILIZANDO AS CURVAS DE RECESSÃO DO RIO DAS ANTAS
}

Determination of the Regulatory Reserve of the Caiua Aquifer on Parana State Using Recession Curves from Rio das Antas

André Celligoi ${ }^{1}$ e Uriel Duarte ${ }^{2}$

\begin{abstract}
RESUMO: $\quad$ A estimativa da reserva reguladora (recarga) do Aquífero Caiuá foi feita a partir da análise das curvas de recessão do Rio das Antas no posto fluviométrico Águas do Jacu $\left(1030 \mathrm{~km}^{2}\right)$, no período de 1978 a 1979. A precipitação média anual nesse período foi de $1385 \mathrm{~mm}$, gerando uma infiltração de 17\%, ou seja, $231 \mathrm{~mm} / \mathrm{ano}$. Extrapolando esse resultado para uma área de $29.000 \mathrm{~km}^{2}$, de ocorrência do Aquífero Caiuá no Estado do Paraná, obtém-se uma reserva reguladora de $6,7 \times 10^{9} \mathrm{~m}^{3} /$ ano.
\end{abstract}

Palavras-chave: Aquífero Caiuá, reservas subterrâneas, recessão.

ABSTRACT: The groundwater reserves of the Caiua Aquifer are extremely important and the hydrographical sub-basin of the Antas River was selected as a local study area for the evaluation of the regulatory reserve (recharge) of that aquifer in the State of Paraná. This regulatory reserve was evaluated as $6,7 \times 10^{9} \mathrm{~m}^{3} /$ year, based on the recession curves of the Antas river at the Águas do Jacu fluviometric station $\left(1030 \mathrm{~km}^{2}\right)$, between 1978 and 1979 . The annual precipitation average in this period was $1385 \mathrm{~mm}$, with infiltration of $17 \%$, meaning $231 \mathrm{~mm} /$ year.

Keywords: Caiuá Aquifer, groundwater reserves, recession.

\section{LOCALIZAÇÃO DA ÁREA}

A área em estudo encontra-se localizada nas regiões norte e noroeste do Estado do Paraná, onde afloram as rochas sedimentares cretáceas do Grupo Bauru da Bacia Sedimentar do Paraná, mais extensivamente a Formação Caiuá, estando delimitada pelos rios Paraná, Paranapanema e Piquiri, respectivamente a oeste, norte e sul, e pelo limite de ocorrência das formações a leste com a Formação Serra Geral, de idade juro-cretácea, perfazendo uma área de cerca de $29.500 \mathrm{~km}^{2}$ (Figura 1).

Inserida entre as coordenadas geográficas de longitudes $51^{\circ}$ e $54^{\circ} \mathrm{W}$ e de latitudes $24^{\circ} 30^{\prime}$ e $22^{\circ} 30^{\prime} \mathrm{S}$, a região abrange vários municípios, tendo entre os mais populosos os municípios de Umuarama, Paranavaí, Cianorte e Nova Esperança, com respectivamente 90.878, 72.972, 52.437 e 25.877 habitantes (IBGE, 1997).

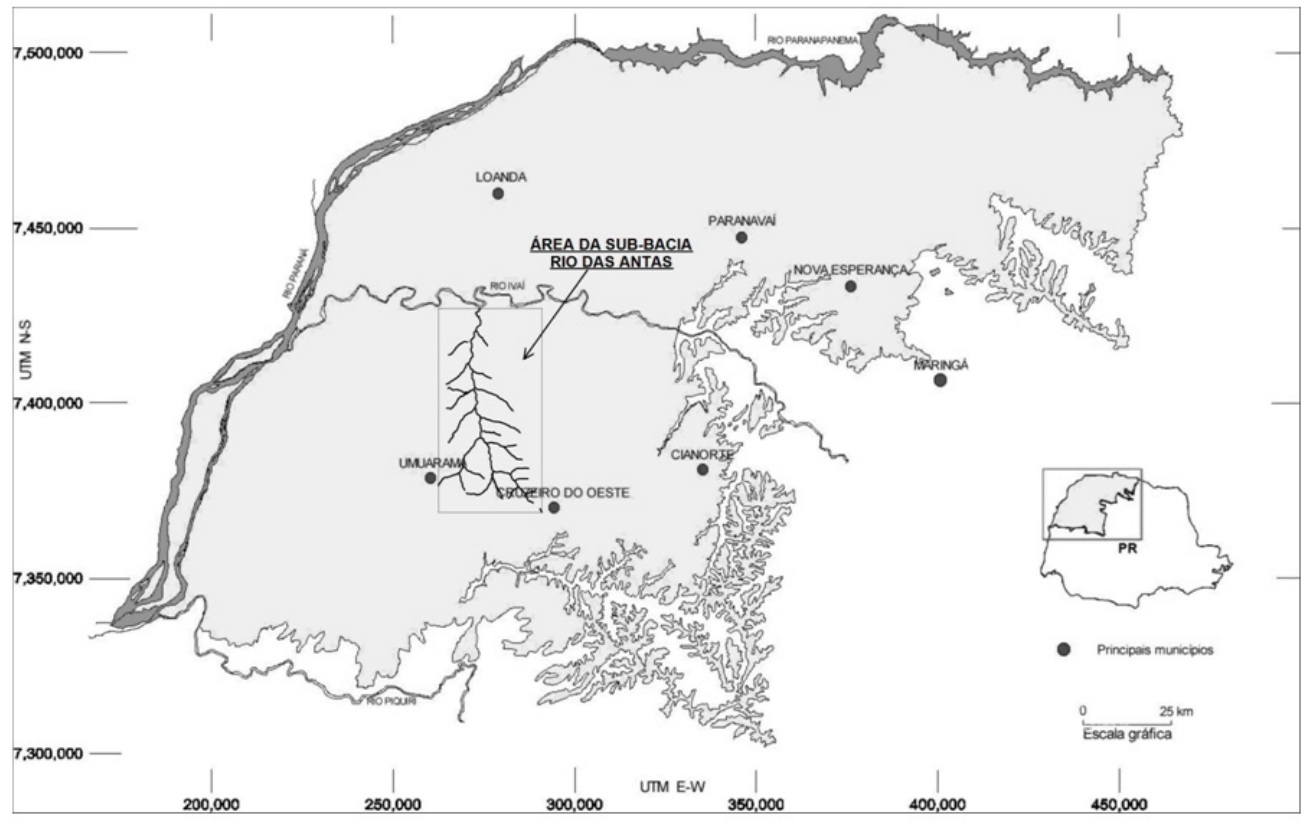

Figura 1: Mapa de localização da área estudada (adaptado de CELLIGOI, 2000).

${ }^{1}$ Departamento de Geociências da Universidade Estadual de Londrina - UEL, Caixa Postal 6001 - 86051-990 Londrina-PR; Fone: 43-33714316; e-mail: (celligoi@uel.br)

${ }^{2}$ Departamento de Geologia Sedimentar e Ambiental -Instituto de Geociências - Universidade de São Paulo. Caixa Postal 11348 -05422-970 - São Paulo-SP. Fone: 11-3818-4226; e-mail: (urduarte@usp.br) 


\section{CONTEXTO GEOLÓGICO}

Em seu contexto geológico, a área de estudo está inserida, segundo Fernandes e Coimbra (1994), sobre a cobertura suprabasáltica neocretácea na Bacia Sedimentar do Paraná, na qual se encontra o Grupo Caiuá e a Formação Adamantina, referente ao Grupo Bauru.

OGrupoCaiuápossuicaracterísticas litológicas, relações estratigráficas e distribuição geográfica de associações faciológicas identificadas no noroeste do Paraná e extremo oeste de São Paulo, divididas em três formações distintas: Formação Goio Erê, Formação Rio Paraná e Formação Santo Anastácio.

A Formação Rio Paraná constitui-se basicamente de arenitos marrom-avermelhados e arroxeados, finos a médios, quartzosos, secundariamente arcoseanos. Exibe notável estratificação cruzada de médio a grande porte, tangencial na base.

A Formação Goio Erê é constituída de arenitos quartzosos frequentemente subacorseanos, marrom-avermelhados a cinza-arroxeados, de granulação fina a muita fina, ocasionalmente média. Dispõem-se em estratos tubulares de poucos metros de espessura com estratificação cruzada, intercalados com bancos de espessura métrica a decimétrica, de aspecto maciço ou estratificação subhorizontal mal definida (FERNANDES \& COIMBRA, 1994). Esta formação tem contato transicional com a Formação Rio Paraná, contatos erosivos com a Formação Serra Geral e com depósitos arenosos cenozóicos.

A Formação Santo Anastácio, embora de ocorrência restrita no Paraná, é constituída de arenitos finos a muito finos, quartzosos, caracteristicamente maciços. São pobremente selecionados, com pequena quantidade de matriz silto-argilosa.

Já a Formação Adamantina, pertencente ao Grupo Bauru, de ocorrência muito restrita, é formada por arenito fino a muito fino, alternado por bancos de lamitos e siltitos.

Além dessas formações referentes à Bacia do Paraná, encontram-se também, depósitos aluviocoluvionares quaternários, adjacentes ao curso dos rios principais, próximos à sua foz, bem como depósitos subaquosos de bacias localizadas.

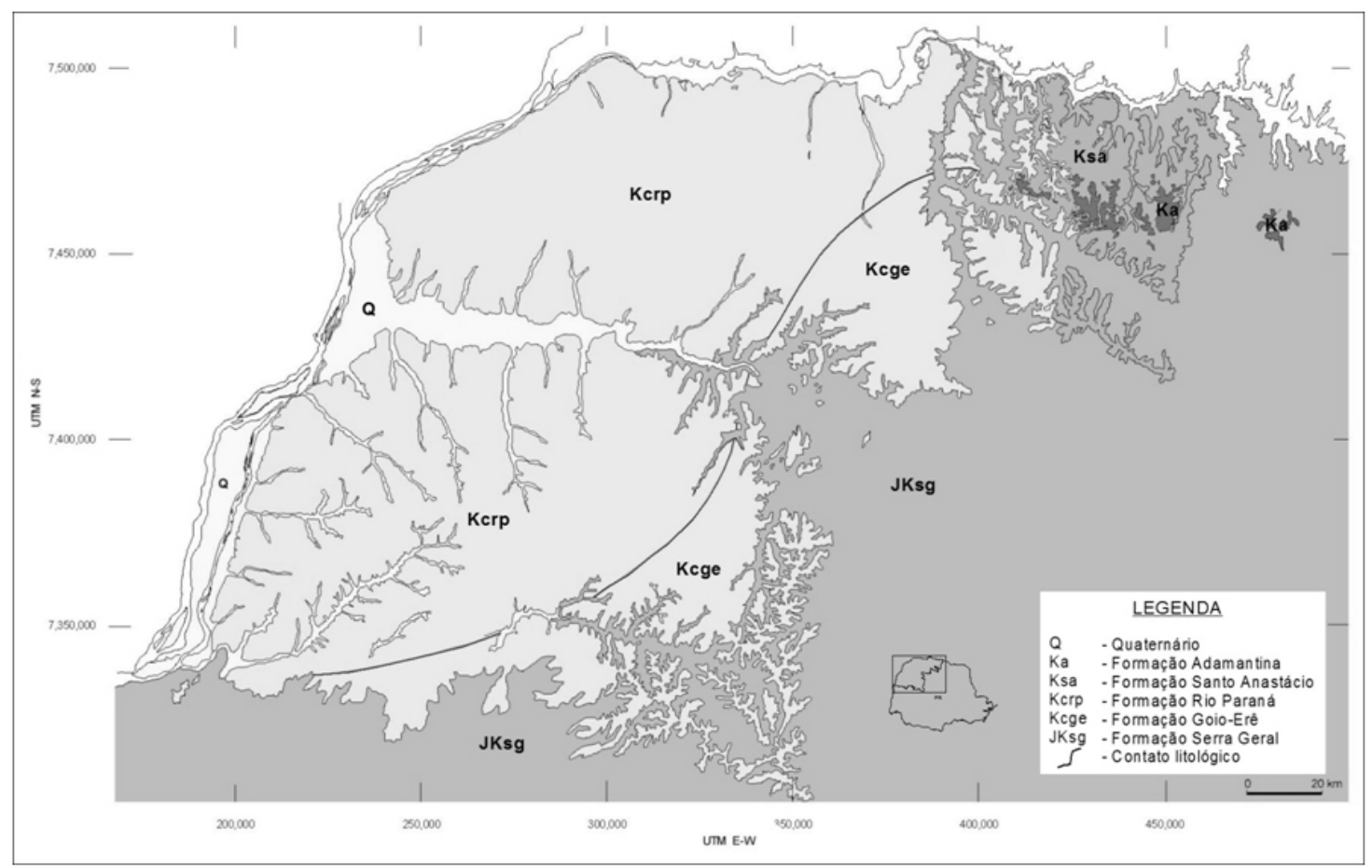

Figura 2: Arcabouço geológico do noroeste do Estado do Paraná (modificado de Fernandes, 1992). 


\section{HIDROGEOLOGIA}

O Aquífero Caiuá consiste em um meio poroso inserido geologicamente nas rochas sedimentares cretáceas pós-basálticas da Bacia Sedimentar do Paraná, as quais, no estado do Paraná, são referidas ao Grupo Caiuá, mais extensivamente a formação Rio Paraná, cujos depósitos sedimentares alcançam espessuras na ordem de 270 metros. A área aflorante da deposição sedimentar apresenta características litológicas relativamente homogêneas, sem grandes quantidades de argilas compactas (CELLIGOI, 2000), o que leva a crer que o Aquífero Caiuá seja considerado como um aquífero livre.

O pacote sedimentar suprabasáltico, principalmente no Estado de São Paulo, constituise, segundo Campos (1987) em um sistema aquífero livre por toda a sua extensão. Fernandes (1992) afirma que o Aquífero Caiuá comportase como livre, por sua maior homogeneidade litológica e decorrente permeabilidade.

Como as formações sedimentares suprabasálticas são todas aflorantes, não existindo um confinamento geológico por formações superiores, exceto as quaternárias, consideraremos os limites atuais do Grupo Caiuá e correlatos, com a Formação Serra Geral sotoposta, como área de afloramento do Aquífero Caiuá, sendo todo ele mapeável em superfície.

Rocha et al. (1982 apud Coelho, 1996), subdividiram o Aquífero Bauru em duas unidades distintas: A Unidade I corresponderia às formações Marília e Adamantina e seria caracterizada por um potencial explorável de médio a baixo, com águas relativamente mais salinizadas, fortemente bicarbonatadas cálcicas e potencialmente incrustantes ou corrosivas. A Unidade II corresponderia à formação Santo Anastácio e ao Grupo Caiuá, sendo caracterizada por um potencial médio a elevado, com águas com teores salinos muito baixos, bicarbonatadas calcomagnesianas, potencialmente corrosivas.

As formações Santo Anastácio e Adamantina ocupam uma porção bastante reduzida dentro do território paranaense, com cerca de 2,8\% em área para a Formação Santo Anastácio e 0,2\% para a Formação Adamantina, existindo uma relativa afinidade geológica entre as formações acima e o Grupo Caiuá, tanto litológica, quanto estrutural.

O Grupo Caiuá ocupa, portanto, o restante dos sedimentos suprabasálticos. Cerca de $6,3 \%$ sobre a área aflorante são identificáveis como sedimentos aluvionares quaternários. Tais sedimentos, embora atinjam uma extensão significativa dentro da área de estudo, principalmente no terraço do Baixo Ivaí, sua exploração com poços tubulares é praticamente inexistente. Isto se deve, principalmente, às condições do relevo plano característico e ao nível freático bastante alto, fatos que viabilizam, em grande parte, a perfuração de poços do tipo cacimba, sendo estes suficientes, muitas vezes, para o suprimento de água das pequenas propriedades da região.

Dessa forma, o Aquífero Caiuá aqui considerado, consiste geologicamente nas rochas sedimentares cretáceas pós-basálticas da Bacia Sedimentar do Paraná, que incluem o Grupo Caiuá propriamente dito e mais a Formação Adamantina, pertencente ao grupo Bauru (Figura 3).

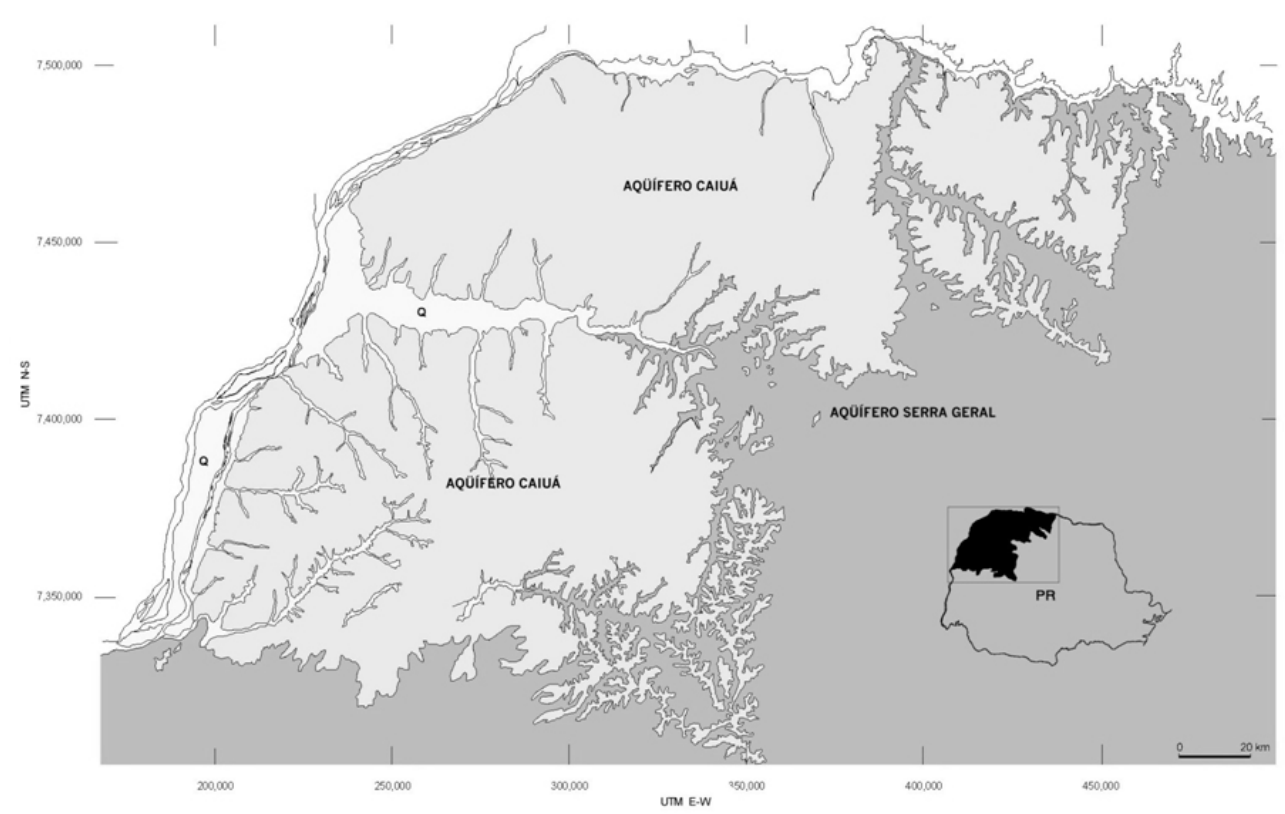

Figura 3: Mapa de extensão e localização do Aquifero Caiuá no Estado do Paraná (adaptado de Celligoi, 2000). 


\section{RESERVAS REGULADORAS}

A reserva reguladora do Aquífero Caiuá no Estado do Paraná corresponde ao volume de água da zona de flutuação sazonal, ou anual, do nível de saturação, contribuindo em sua descarga para a rede hidrográfica na área de afloramento desse aquífero.

Existem diversos critérios de se efetuarem as estimativas, como: variações da superfície potenciométrica em medidas anuais; através da taxa de infiltração; através de infiltrômetros instalados na área, ou através da análise das curvas de recessão dos rios. Este último foi o aplicado no cálculo das reservas reguladoras para este trabalho.

O termo recessão, segundo Domenico e Schwartz (1990), refere-se ao declínio da descarga natural de uma drenagem na ausência de entrada por precipitação e é assumida por leis de decaimento exponencial. O fluxo de base dos rios representa a retirada de água subterrânea do armazenamento, sendo conhecido como recessão de água subterrânea.

Esta recessão é determinada geralmente através de uma série de segmentos de hidrógrafas de um rio, na qual o fluxo de base é considerado, tomandose as medidas de vazão do rio logo após o pico das precipitações. Desse ponto em diante, o fluxo total é o componente do fluxo de base derivado da descarga de água subterrânea na drenagem, pelo menos até as próximas precipitações. A curva gerada em escala logarítmica representa a curva de recessão da água subterrânea e pode ser descrita pela equação a seguir (Domenico e Schwartz, 1990):

$$
Q=Q_{0} e^{-\alpha t}
$$

Onde:

$Q_{0}=$ Descarga do rio no início da recessão $\left(\mathrm{m}^{3} / \mathrm{s}\right)$

$Q=$ Descarga $\left(\mathrm{m}^{3} / \mathrm{s}\right)$ do rio após um período $t$ (dias)

$\alpha=$ Constante de recessão

Para este estudo, foram considerados os dados de vazão fluvial obtidos na Estação Fluviométrica Águas do Jacu, pertencente à SUDERHSA (Superintendência de Desenvolvimento de Recursos Hídricos e Saneamento Ambiental), localizada no rio das Antas, na bacia do rio Ivaí, no município de Douradina. Tal estação foi escolhida, em virtude de o rio encontrar-se inteiramente dentro dos domínios de afloramento da formação Caiuá, bem como na boa confiabilidade dos dados analisados.

A falta de dados mais recentes da estação devese ao fato de que a mesma encontra-se desativada desde 1984, impossibilitando a recuperação dos últimos dados.

A localização da Estação é mostrada na Figura 4.

A partir dos dados de pluviometria diários tomados entre os anos de 1978 e 1983, período no qual a estação permaneceu ativa, observou-se os totais pluviométricos anuais, segundo a Tabela 1 .

Tabela 1: Totais pluviométricos anuais da Estação Fluviométrica Águas do Jacu da SUDERHSA, no período entre 1978 e 1983.

\begin{tabular}{|c|c|}
\hline Ano & Total pluviométrico \\
\hline 1978 & 980 \\
\hline 1979 & 1790 \\
\hline 1980 & 1516 \\
\hline 1981 & 1339 \\
\hline 1982 & 1383 \\
\hline 1983 & 2056 \\
\hline Média & $\mathbf{1 5 1 1}$ \\
\hline
\end{tabular}




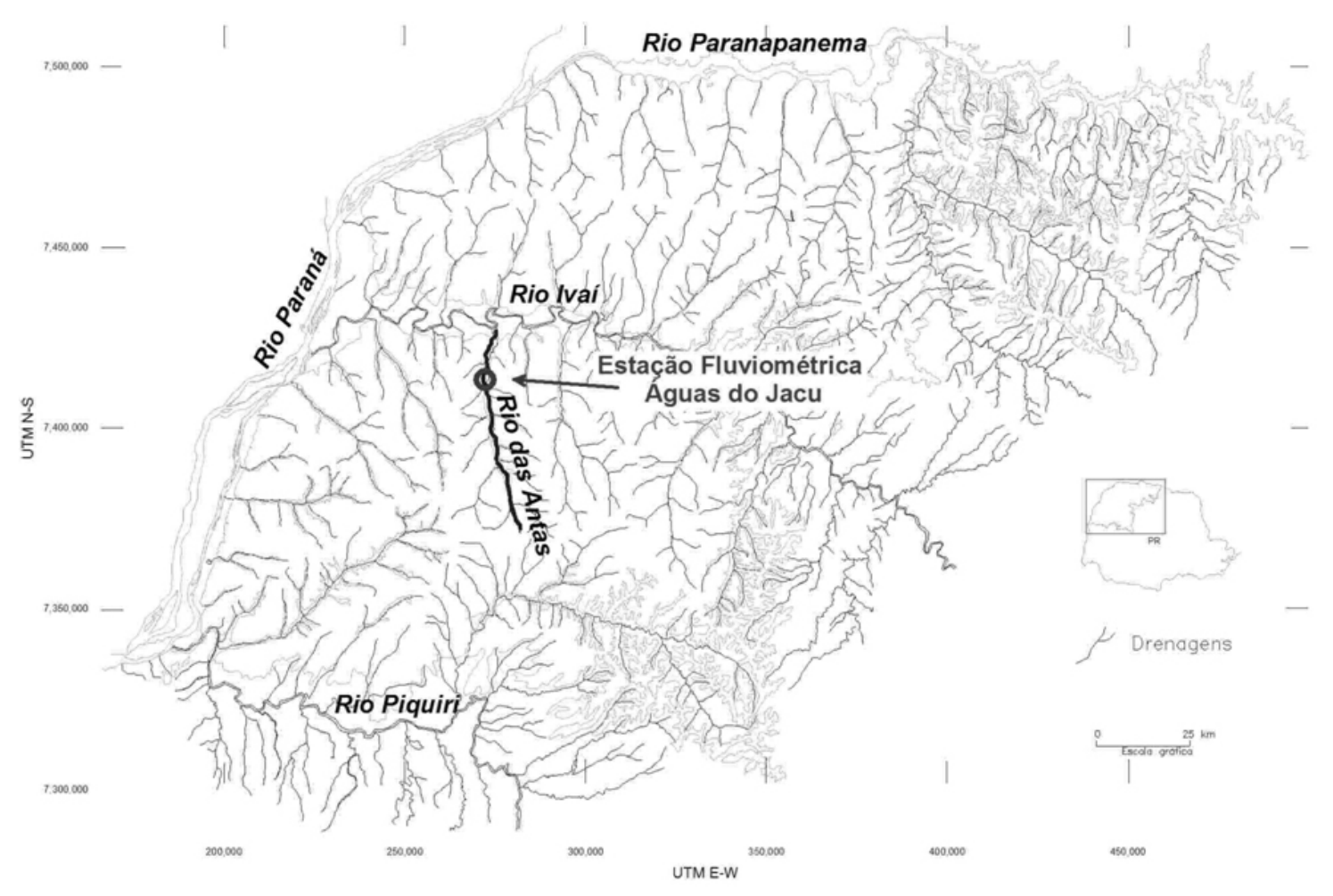

Figura 4: Mapa de localização do rio das Antas e a Estação Fluviométrica Águas do Jacu.

Para o cálculo da reserva reguladora tomaramse como base os dados dos anos de 1978 e 1979, visto que o primeiro é um ano "seco" e o ano seguinte um ano úmido, acima da média para este período nesta estação. Soma-se a isso o fato de as medições de vazão para essa estação só terem sido realizadas até o ano de 1980, a partir do qual, somente dados de alturas diárias de precipitação foram registrados e não mais os de descarga fluvial.

Foram construídos gráficos a partir das medições das vazões do ribeirão das Antas nos anos de 1978 e 1979. Tomando-se primeiramente o ano de 1978, que é um ano "seco" para o período, obtém-se a Figura 5.

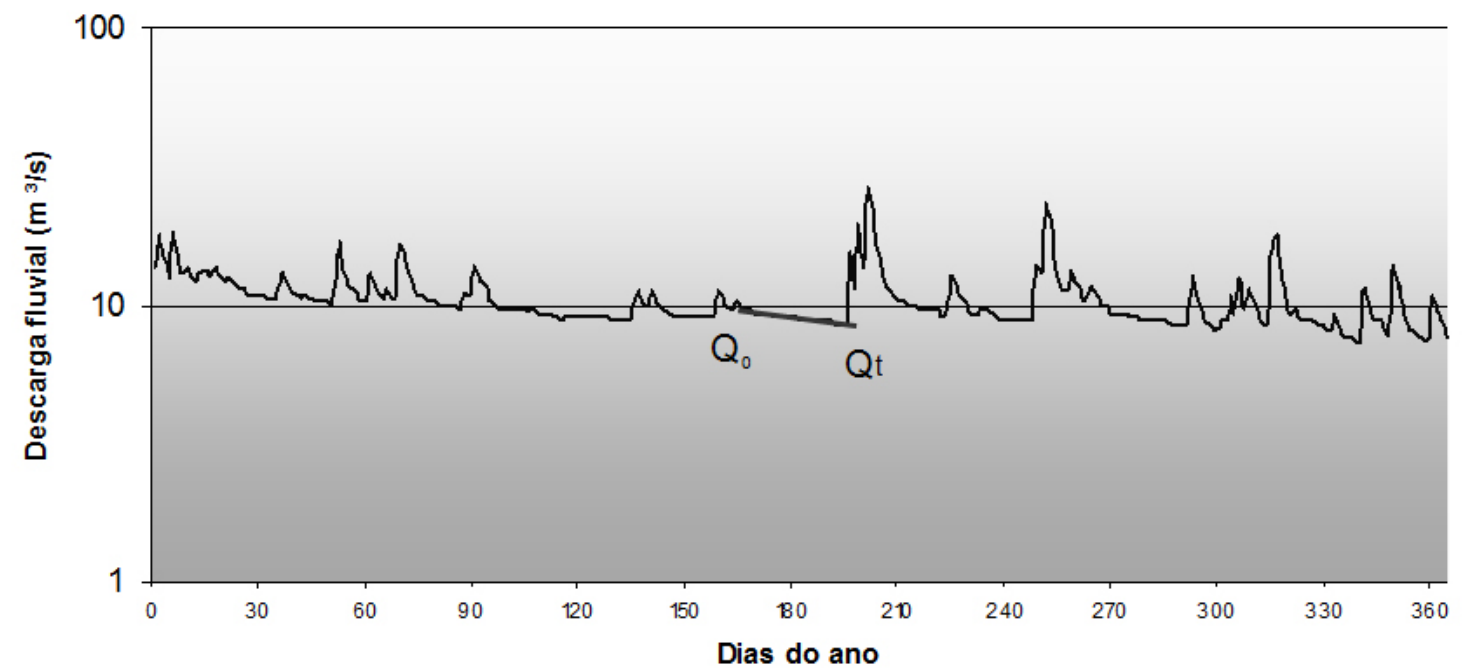

Figura 5: Gráfico da vazão do rio das Antas em 1978, evidenciando o período de recessão. 
Considerando que a descarga medida no rio ao início da recessão $\left(Q_{0}\right)$ é de $9,66 \mathrm{~m}^{3} / \mathrm{s}$ e que a vazão $\left(Q_{t}\right)$ ao cabo de 31 dias é de $8,48 \mathrm{~m}^{3} / \mathrm{s}$, pode-se calcular a constante de recessão, a partir da expressão (1):

$$
\alpha=-\frac{1}{t} \ln \frac{Q}{Q_{0}}
$$

Obtendo-se um valor de $\alpha$ de 0,004 .

O volume infiltrado na bacia contribuinte é dado por:

$$
V_{0}=\frac{Q_{0} .86 .400}{\alpha}
$$

Obtendo-se o valor de $2,08 \times 10^{8} \mathrm{~m}^{3} / \mathrm{ano}$.
Sendo a área da bacia contribuinte para a estação Águas do Jacu $(A)$ de $1,03 \times 10^{9} \mathrm{~m}^{2}$, a restituição média anual para o ano de $1978\left(h_{l}\right)$ pode ser calculada por:

$$
h=\frac{V_{0}}{A}
$$

Então, tem-se: $h_{l}=202 \mathrm{~mm} / \mathrm{ano}$

Para o ano de 1979, que se constitui em um ano "médio" a "úmido", pelo mesmo procedimento tem-se o cálculo da restituição média anual (Figura 6).

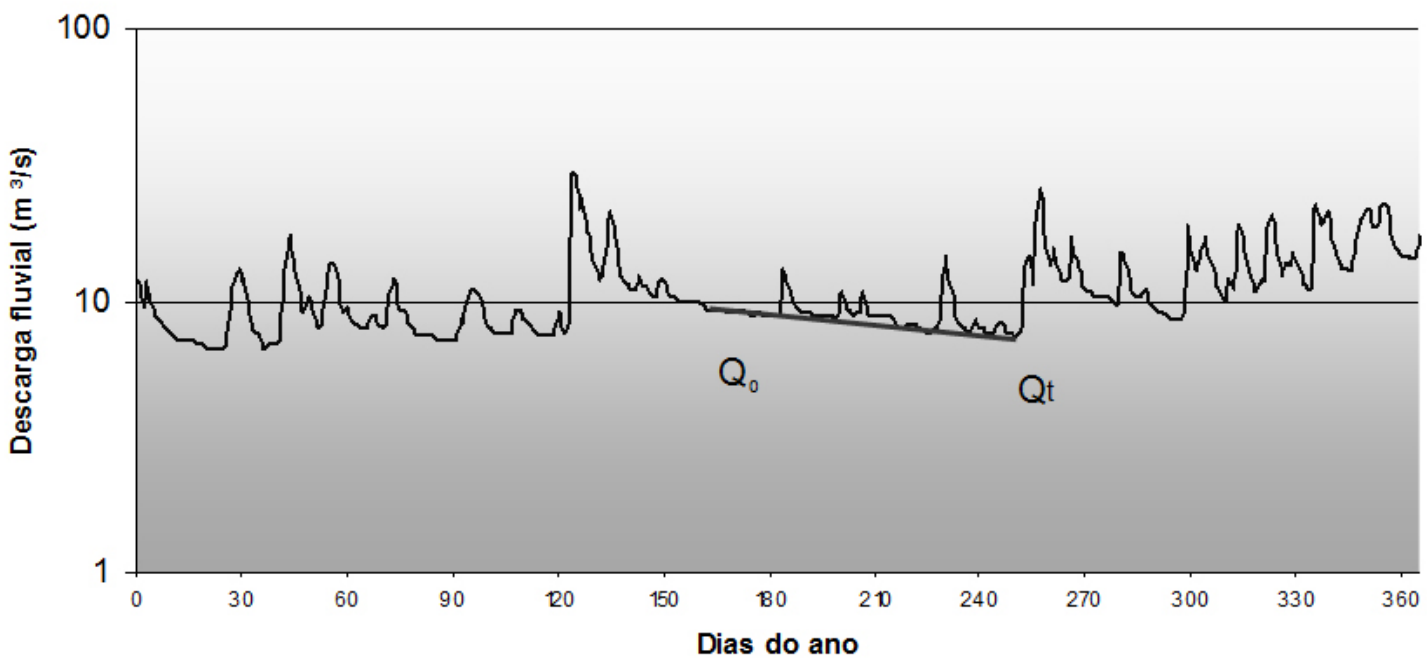

Figura 6: Gráfico da vazão do rio das Antas em 1979, evidenciando o período de recessão.

Sendo que a descarga inicial $\left(Q_{0}\right)$ é de $9,66 \mathrm{~m}^{3} / \mathrm{s}$ e a vazão $\left(Q_{t}\right.$ ) passados 88 dias é de $7,40 \mathrm{~m}^{3} / \mathrm{s}$, a partir da mesma forma de cálculo para o ano de 1978, obtém-se um valor de $\alpha$ de 0,003 .

$\mathrm{O}$ volume infiltrado $\left(V_{0}\right)$ na bacia contribuinte, dado pela equação (2), é estimado em $2,78 \times 10^{8} \mathrm{~m}^{3} /$ ano. Sendo a área da bacia contribuinte $(A)$ igual a $1,03 \times 10^{9} \mathrm{~m}^{2}$, a restituição média anual para o ano de $1979\left(h_{2}\right)$ pode ser calculada por (3), obtendo-se o valor de $260 \mathrm{~mm} / \mathrm{ano}$.

Sendo a média pluviométrica anual na estação pluviométrica Águas do Jacu (Tabela 1) igual a 1385 mm no período de 1978-1979, a restituição média $\left(h_{m}=231 \mathrm{~mm} / \mathrm{ano}\right)$ a partir dos valores de $h_{1}$ e $h_{2}$, perfaz $17 \%$ da pluviometria, valor este bem próximo de outros obtidos por diversos autores para o Aquífero Bauru como um todo, entre eles Rebouças (1976).

Para o cálculo da reserva reguladora propriamente dita, utilizou-se o valor médio de restituição para os anos de 1978 e 1979. A área de ocorrência do Aquífero Caiuá no Estado do Paraná $\left(A_{C}\right)$ é de aproximadamente $2,9 \times 10^{10} \mathrm{~m}^{2}$.

A extrapolação da área da bacia contribuinte para a área de ocorrência do Aquífero Caiuá é possível em virtude da relativa homogeneidade lateral das 
formações constituintes.

Dessa forma, a reserva reguladora $\left(\mathrm{R}_{\mathrm{r}}\right)$ pode ser calculada por:

$$
\mathrm{R}_{\mathrm{r}}=\mathrm{A}_{\mathrm{C}} \times h_{m}
$$

Obtendo-se o valor de $6,7 \times 10^{9} \mathrm{~m}^{3} / \mathrm{ano}$.

\section{CONCLUSÕES}

A sub-bacia do rio das Antas está inserida na região noroeste do estado do Paraná, sobre a qual afloram as rochas sedimentares suprabasálticas referentes ao Aquífero Caiuá. Em seu contexto geológico a área de estudo localiza-se sobre as formações que constituem o Grupo Caiuá, mais extensivamente a Formação Goio Êre em contato transicional com a Formação Rio Paraná e contato erosivo com a Formação Serra Geral.

O Aquífero Caiuá consiste em seu pacote sedimentar um meio poroso, com características relativamente homogêneas, sem grandes quantidades de argila compactas, por isso, considerado como um sistema aquífero livre, podendo ocorrer pressões de confinamento localmente.

As reservas reguladoras, calculadas a partir da curva de recessão do rio das Antas nos anos de 1978 e 1979 foram de $6,7 \times 10^{9} \mathrm{~m}^{3} / \mathrm{ano}$.

\section{REFERÊNCIAS BIBLIOGRÁFICAS}

CAMPOS, H.C.N.S. Contribuição ao estudo hidrogeológico do Grupo Bauru no Estado de São Paulo. São Paulo, 1987. Dissertação (Mestrado). Instituto de Geociências, Universidade de São Paulo.

CELLIGOI, A. Hidrogeologia da Formação Caiuá no Estado do Paraná. São Paulo, 2000. 96 f. Tese (Doutorado). Instituto de Geociências, Universidade de São Paulo.

COELHO, R. O. Estudo hidroquímico e isotópico do Aquífero Bauru, sudoeste do Estado de São Paulo. São Paulo, 1996. Dissertação (Mestrado). Instituto de Geociências, Universidade de São Paulo.

COSTA, W. D. Avaliação de reservas, potencialidade e disponibilidade de aquíferos. In: CONGRESSO BRASILEIRO DE ÁGUAS SUBTERRÂNEAS, (10.: 1998: São Paulo), Anais... São Paulo, 1998, ABAS,CD-ROM.

DOMENICO, P. A. ; SCHWARTZ, F. W. Physical and Chemical Hydrogeology. John Wiley \& Sons, Singapore, 1990.

FERNANDES, L. A. \& COIMBRA, A. C. O Grupo Caiuá: revisão estratigráfica e contexto deposicional. Revista Brasileira de Geociências. SBG, São Paulo, v. 24 n. 3 p. 164-176, 1994.

FERNANDES, L. A. A cobertura cretácea suprabasálticanoParanáePontal doParanapanema: os grupos Bauru e Caiuá,. São Paulo, 1992. 129 f. Dissertação (Mestrado). Instituto de Geociências, Universidade de São Paulo.

IBGE. Contagem da População 1996 - Sistema de Recuperação de Informações Municipais. 1997, IBGE. CD-ROM.
PARANÁ
(Estado).
INSTITUTO
AGRONÔMICO DO PARANÁ - IAPAR ÁREA DE ECOFISIOLOGIA. Resumos anuais de temperaturas médias e precipitação nas estações de Cianorte, Umuarama e Paranavaí. 1972 a 1998.
PARANÁ
(Estado).
INSTITUTO

AGRONÔMICO DO PARANÁ-IAPAR. Boletins climatológicos das estações meteorológicas da região noroeste do Estado do Paraná. 1972 a 1998.

PARANÁ (Estado). SUPERINTENDÊNCIA DE DESENVOLVIMENTO DE RECURSOS HÍDRICOS E SANEAMENTO AMBIENTAL - SUDERHSA. Secretaria de Estado do Meio Ambiente do Paraná . Cadastro geral de poços profundos.

PARANÁ (Estado). SUPERINTENDÊNCIA DE DESENVOLVIMENTO DE RECURSOS HÍDRICOS E SANEAMENTO AMBIENTAL - SUDERHSA. Secretaria de Estado do Meio Ambiente do Paraná. Dados das estações fluviométricas de Águas do Jacú e Sítio Santo Antonio. 1978 a 1983.

PARANÁ (Estado). SUPERINTENDÊNCIA DE DESENVOLVIMENTO DE RECURSOS HÍDRICOS E SANEAMENTO AMBIENTAL - SUDERHSA - Centro de Monitoramento Hidrológico do Paraná. Secretaria de Estado do Meio Ambiente do Paraná . Médias mensais pluviométricas entre 1974 e 1984.

REBOUÇAS, A.C. Recursos hídricos 
subterrâneos da Bacia do Paraná - análise de préviabilidade. São Paulo, 1976, 143 f. Tese (Livre Docência) Instituto de Geociências, Universidade de São Paulo.

ROCHA,
CAMPOS, H.C.N.S.; CAIXETA, J.B. Tentativa de zoneamento das características hidráulicas do Aquífero Bauru. In: SBG e ABAS. ENCONTRO DE GEOLOGIA E HIDROGEOLOGIA, Anais... 1982, São Paulo. 